\title{
Municipal Heating Grid Load Predictions for Improved Control of Heating and Cogeneration Plants
}

\author{
Aneta Strzalka ${ }^{1}$, Jacek Kalina ${ }^{2}$, Rafal Strzalka ${ }^{1}$, Ursula Eicker ${ }^{1}$ \\ ${ }^{1}$ Stuttgart University of Applied Sciences, Stuttgart, Germany \\ ${ }^{2}$ Silesian University of Technology, Gliwice, Poland
}

\begin{abstract}
Presently, there are substantial financial efforts to improve heating plants' control and system optimisation based on heat load predictions. In this paper two methods for heat load predictions in urban areas are demonstrated. The first one is an in-house Urban Energy Platform called SimStadt, which is based on 3D CityGML buildings models and its characteristics. The second approach uses long-term measurement data processed by an Artificial Neural Network. Both methods show accurate results on the annual basis at citywide scale.
\end{abstract}

Furthermore, high correlation between measured and predicted hourly load profiles enables forecasts to be used as guidelines for efficient energy generation, which will increase overall system efficiency.

\section{Introduction}

\section{Aim and approach}

Resource efficient, price competitive and low-carbon district heating systems require rational decisions on operation of productive assets. Therefore, great effort is being undertaken nowadays to make district heating systems more effective. Important present research activities are oriented toward improvement of heating plants control and system optimisation based on load predictions. With load forecasts, the plant operator is able to decide heating unit dispatch, generation profile, grid forward temperature and storage operation in order to satisfy a given optimization criteria, i.e. objective function. However, the critical issue of the optimisation task is accurate prediction of head demand for at least one day ahead system operation. Planning of heat production and storage as well as equipment dispatch are of high importance especially in the case of cogeneration plants offering electricity on the balancing market. This is due to significant impact of plant operation characteristics on plant economics.

In this paper two different techniques for heat load predictions in urban areas are presented and the main problems related to their development are discussed. Special emphasis is put on the development of an urban area-wide 3D model-based heat load forecasting method, which would enable predictions of heating network hourly load profiles. The in-house Urban Energy Platform, called SimStadt (SimStadt, 2018), uses models of all buildings within the studied areas based on the 3D CityGML standard (Gröger et al., 2012). Firstly, some results for a German case study area, Scharnhauser Park (SHP), are shown, as the methodology was developed using this area. This method was then tested on the City of Krosno, Poland, to quantify transferability to different climates. The numerical modelling results are compared with an Artificial Neural Network (ANN) trained on the long-term historical data. In order to verify the models, both techniques were applied to the municipal heating system of the City of Krosno, Poland, where detailed and long-term measurement data were available.

Scientific Innovation and relevance

According to Heat Roadmap Europe (2017), Europe consumes half of its final energy for heating and cooling purposes. Around 9\% of this is delivered by district heating systems. Considering that typical energy conversion efficiency from a heating plant is around $80 \%$ to $90 \%$ depending on technology, grid losses are around $10 \%$ to $15 \%$ and there are additional energy losses at buildings that depend on system performance, one can conclude that losses account for a substantial portion of European primary energy input, approximately 1,542.7 million tons of oil equivalent (Eurostat, 2016). According to UNEP Report (2017) systemic inefficiencies result in massive economic and social costs, and act as a major barrier to universal access to modern energy. Therefore, new concepts and techniques to optimise district heating systems and to balance energy load and generation are needed. In this work an innovative approach, similar to that of Nouvel et. al (2017) and Monien D. et al. (2017) is presented. It enables analysis and simulation of heat demand profile of an entire urban area. Presently, most of commonly employed methods are restricted only to a limited number of buildings with sufficient data. This is mainly because detailed data acquisition at the city-scale is very difficult and even unrealistic. Therefore, in this paper a 3D model-based method using very few input data is presented and validated using real measurement data. The presented approach is also innovative as the weak point of most city-scale heat demand forecast techniques is the lack of a validation process (Strzalka et. al, 2011).

\section{Case Study Areas}

\section{Scharnhauser Park}

The German case study area, Scharnhauser Park (SHP) is a mixed residential-commercial area that is located on the southern border of Stuttgart, Germany, covering 150 hectares and with 10,000 inhabitants. The area is a former 
military zone, in which office space, residential areas and parks have been integrated.

The urban project is designed to be an exemplary ecological community development project, in which low energy building standards were prescribed for all plots since the early 1990s, when the American army vacated SHP, and paved the way for the city to develop a new quarter there. The combination of work places, residential areas and public parks led to an integrated living and transportation concept with high comfort and low energy consumption. About $80 \%$ of the heat demand of SHP is supplied by renewable energy sources. The main portion of heating and electricity is delivered to the buildings in SHP from a 6.3 MW thermal and $1 \mathrm{MW}$ electric wood fired co-generation plant. The heat is delivered to the buildings through a $13.5 \mathrm{~km}$ long heating network. In 1993 the local supply company, Stadtwerke Esslingen (SWE), took over the district heating system of Nellingen Baracks from the US Forces, when the network was supplied with steam. The former infrastructure has been taken out of operation and was replaced by a new hot water network. The structure of the heating network was coordinated with the development plan of the road system in this area (Figure 1).

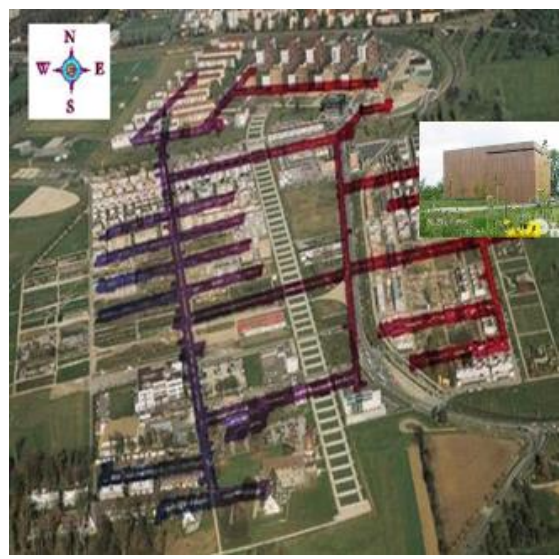

Figure 1: Residential Area Scharnhauser Park [Source: GoogleEarth]

\section{Krosno}

The City of Krosno is located in south-eastern Poland, with a population of approximately 47,000 . The total length of the municipal heating network is $29.5 \mathrm{~km}$ and with a capacity of $1276.1 \mathrm{~m}^{3}$. There is a total of 169 heat consumers (heat substations). Average duration of the heating season is 211 days. The heating power ordered by consumers is $46.5 \mathrm{MW}$ and the peak power of the heating plant is about 29.0 MW. The amount of heat delivered to the grid is about $253,700 \mathrm{GJ} / \mathrm{year}$. Heat is used for heating and domestic hot water production by local communities, administration and public buildings, and local businesses. The distribution of district heating consumption is as follows: households - $70 \%$, public facilities (schools, kindergartens, hospitals, and offices) $-24 \%$, service facilities $-6 \%$.

\footnotetext{
${ }^{1}$ https://www.lgl-bw.de/lgl-internet/opencms/de/index.html
}

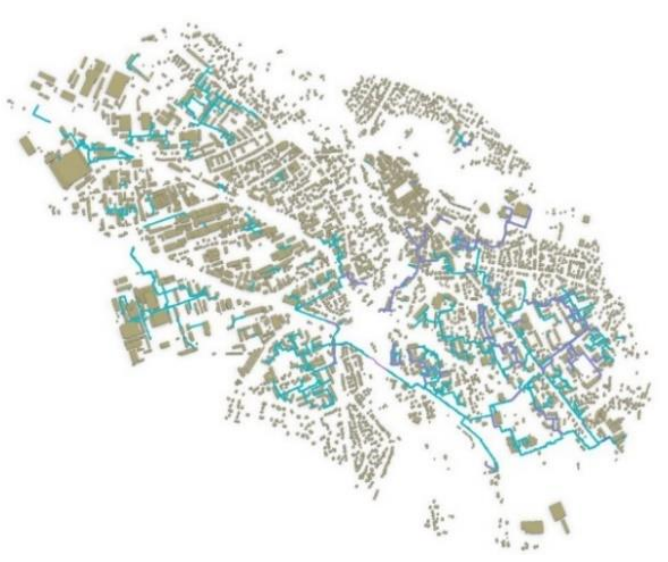

Figure 2: The City of Krosno (buildings shape and heating networks)

\section{Methods}

Data acquisition and pre-processing

\section{Geometries}

In order to perform a building simulation at district level, heating model inputs such as building envelope, volume and orientation of building surfaces are derived from the 3D CityGML models (Braun et al., 2018).

For the residential area of SHP, a 3D CityGML model in a Level of Detail LoD1 and LoD2 were obtained from the State Office for Geoinformation and Land Development Baden-Württemberg (in German: Landesamt für Geoinformation und Landentwicklung BadenWürttemberg $^{1}$ ) in Stuttgart (Figure 3). LoD1 is a simple block model of a 3D building including walls and information about average building height. LoD2 adds a geometric information about the roof structure.

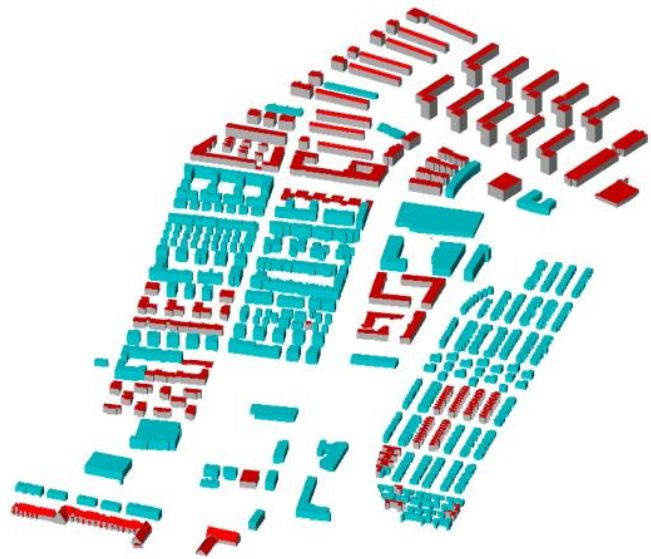

Figure 3: CityGML model of SHP (mixed LoD1 and LoD2)

These models have also included the information about the building function for each building, but the information about the year of construction had to be put separately into the CityGML-file by using a special FMEWorkbench, see Figure 4. Each building has its own GML-ID and the information on building function and the year of construction. 


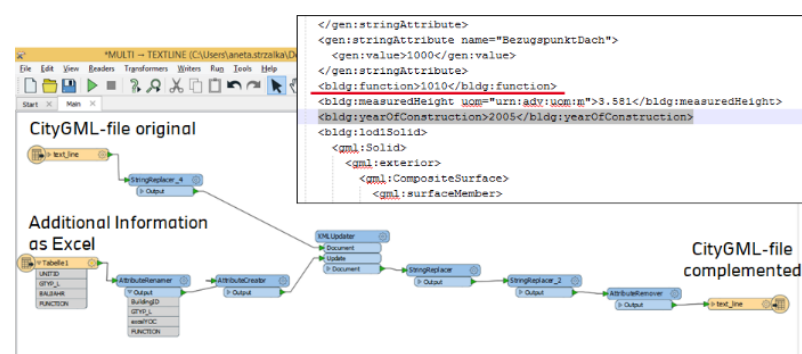

Figure 4: Scheme of the FME-Workbench for adding the information into the CityGML-File

For the City of Krosno such a model was not available and it had to be created. Therefore, a DXF map obtained from the municipality was used to generate a shape file of the building footprints. Then these buildings' footprints together with the information of the building's height (delivered by district heating company of Krosno) were used to generate a 3D CityGML model using an FME Workbench. As in the case of SHP, the information about the year of construction had to be added into this CityGML-file in order to create a file, compatible for use in the simulation.

\section{Monitoring data}

The annual heat consumption data for the residential area SHP was delivered by the Stadtwerke Esslingen GmbH as an Excel-File and then uploaded into an Access-Database in order to connect it with the appropriate GML-ID from the CityGML-File.

The monitoring data from the City of Krosno, e.g. annual heat consumption data for each building for the year 2016 and 2017 were delivered by the district heating company of Krosno. The annual heat load data for the whole district heating network for these years was also delivered.

\section{Weather data}

The hourly weather data for SHP was delivered by the utility company Stadtwerke Esslingen GmbH in hourly resolution, which have been measured using a weather station installed on the roof of the biomass plant, which is supplying SHP with energy.

As the weather station at the heating plant of City of Krosno was installed in 2018, weather data at hourly resolution from 2016 and 2017 was generated using detailed measurements for the City of Krosno, stored in the open access database of the National Research Institute of Meteorology and Water Management ${ }^{2}$.

List of data/variables used for both cases

For SHP the following data and variables were used:

- Geometries by using 3D CityGML models.

- Year of Construction

- Building type

- Building function

- Annual heat consumption data for each individual building for the year 2009

\footnotetext{
${ }^{2}$ http://www.imgw.pl/en/

${ }^{3}$ zafh.net - Center for Applied Energy

${ }^{4}$ https://www.moss.de/
}

- $\quad$ Hourly weather data for the year 2009

For the City of Krosno following data were used:

- Geometries (Building footprints from the DXFMap, Building height)

- Year of Construction

- Building Type

- Building Function

- Annual heat consumption data for each individual building for the years 2016 and 2017

- Hourly heat load profile delivered through the district heating network for the year 2016

- Hourly weather data for the years 2016 and 2017

- Refurbishment state of the buildings

\section{SimStadt Urban Energy Platform}

SimStadt (SimStadt, 2018) is an in-house Urban Energy Platform, jointly developed by the researchers from zafh.net $^{3}$, Geoinformatics at HFT Stuttgart, companies M.O.S.S. GmbH ${ }^{4}$ and GEF $\mathrm{AG}^{5}$. The platform aims to support urban planners and city managers with defining and coordinating low-carbon energy strategies for their cities with a variety of multi-scale energy analyses. SimStadt enables the simulation of heat demand, including refurbishment scenarios, generation of district heating network, etc. The heat demand calculation is calculated according to the German Directive DIN V 18599 (DIN e. V., 2010).

The variables needed for SimStadt are as follows:

- 3D CityGML model of individual buildings

- Building Function

- Building Type

- Year of Construction

- Hourly weather file in .tmy3 format

Results

Forecasting method using SimStadt

Scharnhauser Park

SimStadt, using the 3D CityGML models, was used to forecast the heat demand of the individual buildings in the residential area of SHP. The calculated values were then compared with the measured ones and percentage deviations between the data was visualized in Figure 5. 

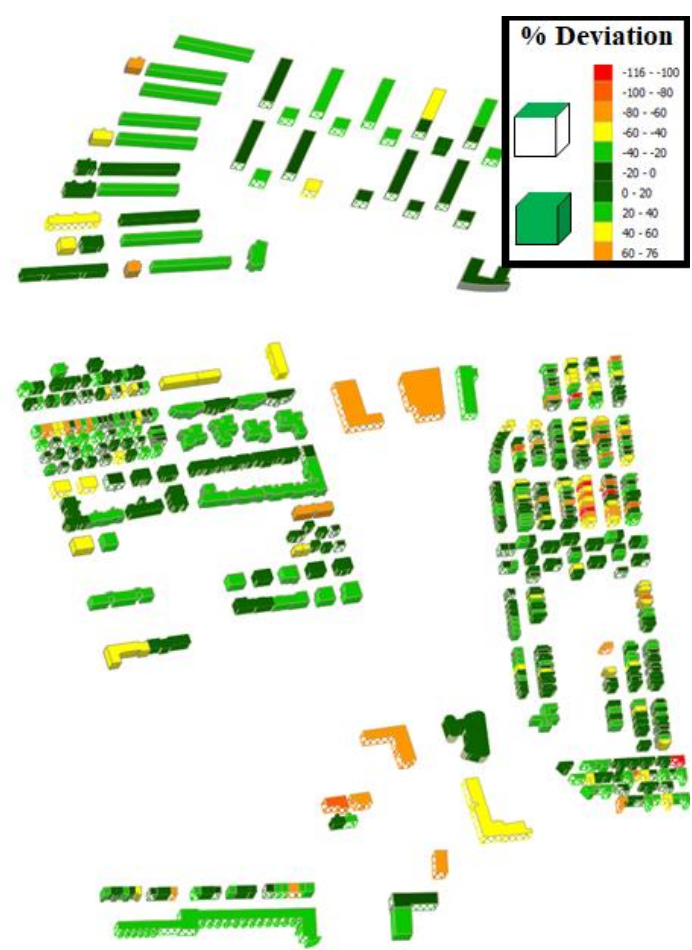

Figure 5: QGIS-Visualization of the \% deviations between measured and calculated values for SHP (2009)

Figure 6 shows again the measured and calculated annual values of all buildings in SHP as well as the percental deviations between these data. Deviations at the individual building level range $+/-75 \%$. If the total consumption of all buildings is summed up, the deviation reduces to $6 \%$.

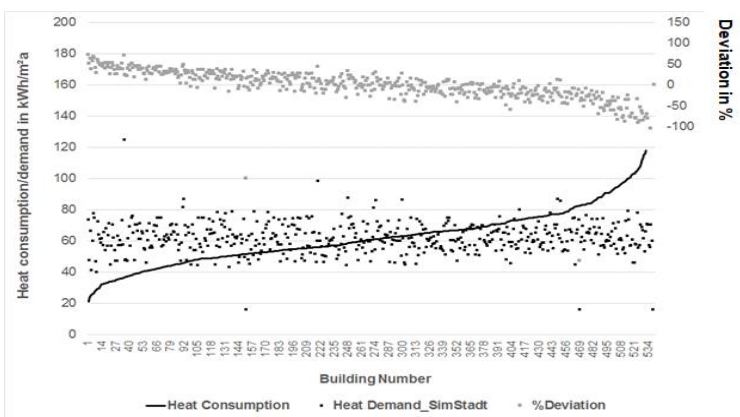

Figure 6: Comparison between measured and calculated annual values (2009) for SHP

These deviations are caused due to some buildings having installed rooftop thermal collectors, which reduce the heat consumption delivered through the district heating network. SimStadt does not model this feature and therefore the calculated heat demand is much higher than the measured heat consumption.

Another point are measurement uncertainties in the building geometries, particularly building height, due to some mistakes in the 3D CityGML file.

One important factor, which contributes to deviations between measured and calculated values is building user behavior, which SimStadt considers as standard constant values (e.g. set-point temperature of $20^{\circ} \mathrm{C}$, air change rate of $0.5 \mathrm{~h}^{-1}$, etc.). In the reality there are strong variations regarding the user behavior between different users.

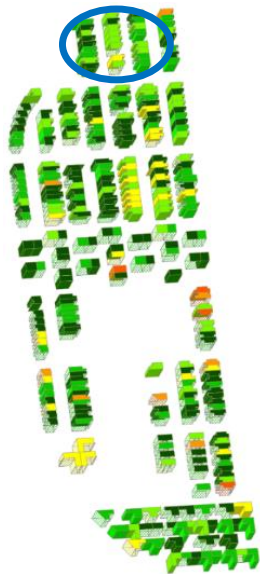

\section{Abs Deviation in $\mathbf{k W h} / \mathbf{m}^{2} \mathbf{a}$}

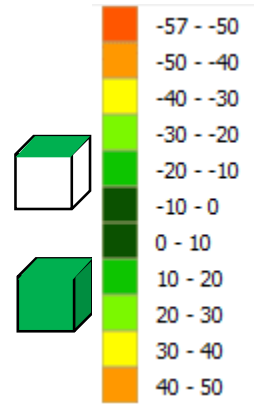

Figure 7: QGIS visualization of the absolute annual deviations for row houses of SHP (2009)

For example, Figure 7 shows in the blue oval a group of row houses, which have nearly identical building type and year of construction. As in Figure 8 the calculated values of heat demand for these buildings are almost at the similar level (between 60 and $80 \mathrm{kWh} / \mathrm{m}^{2} \mathrm{a}$ ), because the buildings are almost similar, the measured values deviate strongly between 20 and $100 \mathrm{kWh} / \mathrm{m}^{2} \mathrm{a}$, which means individual user behaviour plays an important role here.

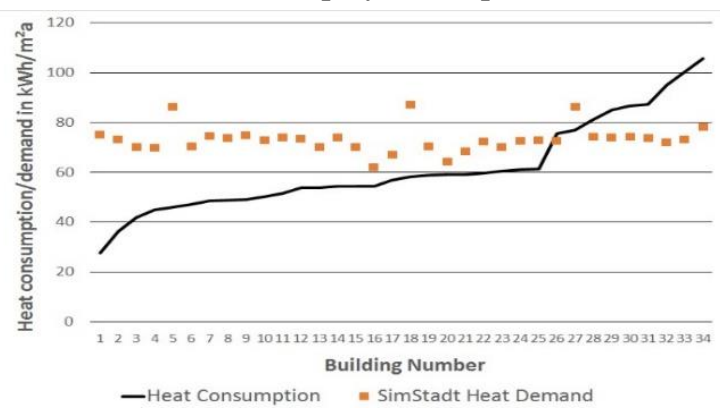

Figure 8: Comparison between measured and calculated values for a group of similar row houses (2009)

The deviations on the individual building level remain after summing them up to the district level (Figure 9).

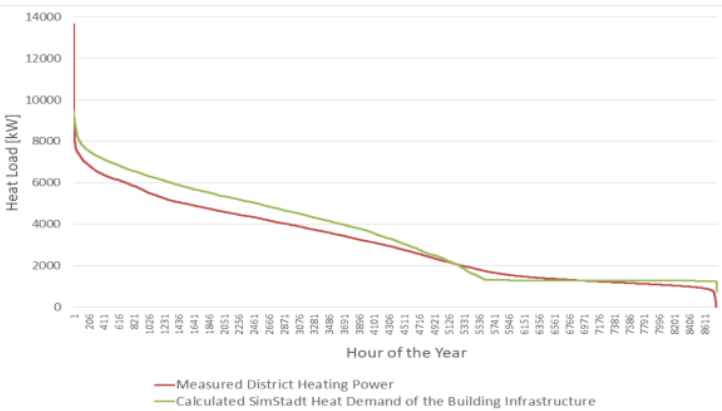

Figure 9: Comparison between measured and calculated sorted annual load curves for SHP (2009).

The fit between the sorted annul load curves on the hourly basis seen above shows good agreement between the measured and calculated values.

\section{Krosno}

SimStadt was also used to calculate the annual heat demand for each individual building in the City of Krosno for 2016. The results in $\mathrm{kWh} / \mathrm{m}^{2} \mathrm{a}$ are shown in Figure 10. 


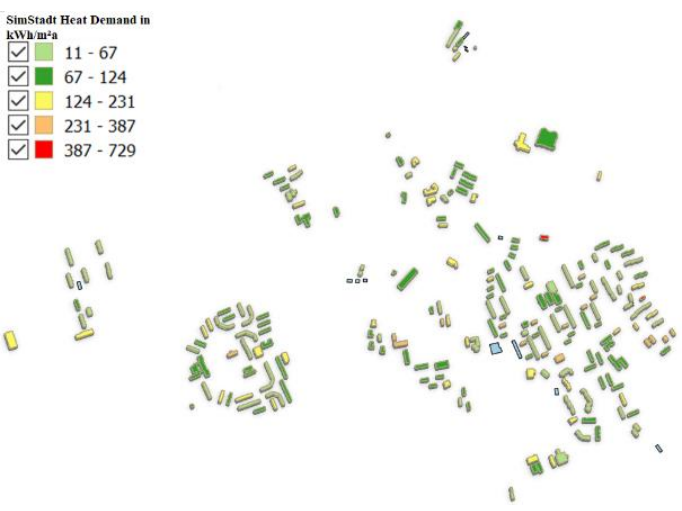

Figure 10: QGIS-Visualization of the calculated values of the heat demand for Krosno using SimStadt (2016)

The SimStadt calculation considers the refurbishment status of individual buildings according to data provided by the district heating company of the City of Krosno. As SimStadt supports only three refurbishment cases: a moderate package ("medium"), which corresponds to the practical implementation of refurbishment measures to achieve the minimum requirements of the German EnEV 2014, an "advanced" scenario, which is corresponding to what is technically feasible today and complies with the insulation standards of passive houses, and a third scenario corresponding to the German EnEV 2016, only these cases could be considered in the calculation. In all three scenarios, a set of measurements for each building, e.g. insulation of the ceiling, façade roofs or replacement of windows was modelled using the recommended measures of the IWU building typology library (IWU, 2015).

The calculated values were then compared with the annual heat consumption values. The results of the comparison between the measured and simulated values (Figure 11) also show strong deviations on an individual building level. Deviations over $50 \%$ might be caused by user behaviour, which is considered in SimStadt with constant parameters, as well as by improper classification of assumption of refurbishment state of these buildings.

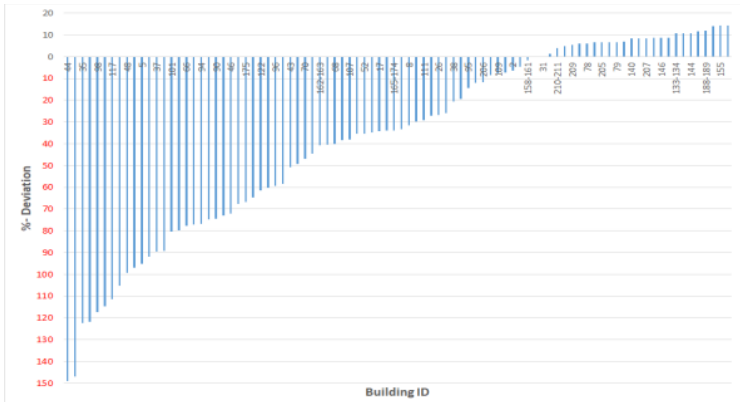

Figure 11: Percental deviations between calculated and measured annual values for the City of Krosno (2016)

If the heat consumption/demand of all individual buildings are summed up, the total percent deviation over 2016 between them is only $2 \%$.

However, the deviations at individual building level will remain after summing them up the district scale (Figure 12).

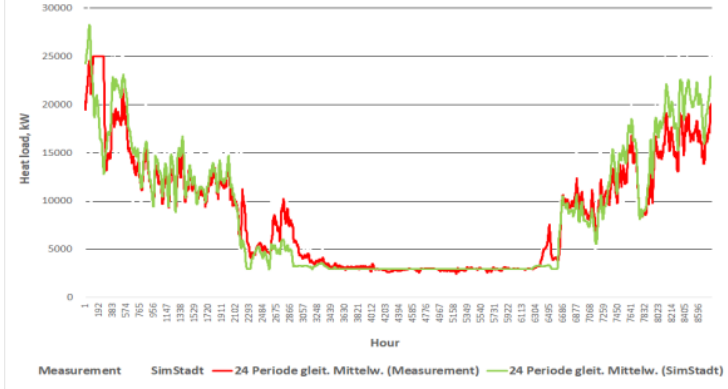

Figure 12: Comparison between measured and calculated hourly heat load profiles for Krosno (2016)

As seen in Figure 12 there is a high correlation at district level, as the user and other depended factors relevant for individual building calculation average out at the whole district level.

From this comparison the hourly domestic hot water (DWD) load profiles play an important role in the deviations between measured and calculated values. In reality the DWD load profiles varies during the day, with peaks during the office times, as seen in Figure 13. SimStadt treats DWD as a constant value for each building type.

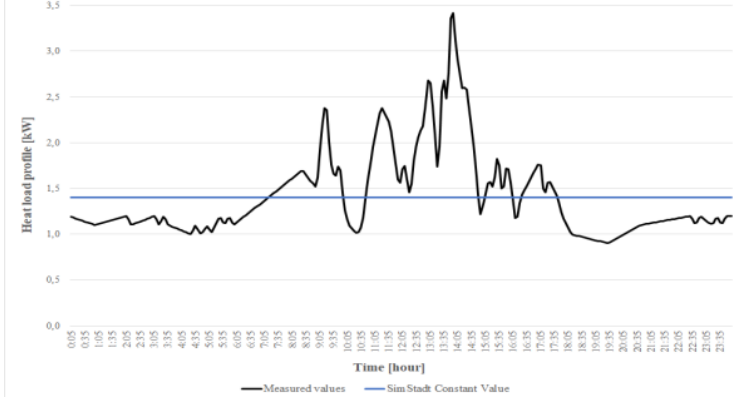

Figure 13: Measured DWD load profile and SimStadt standard constant value for an office building of Krosno In case of residential buildings, the measured DWD load profile of one sample building shows significant peaks during both the morning and evening hours (Figure 14). In contrast is SimStadt a standard constant value, which underestimates the measured load $83 \%$ of the time.

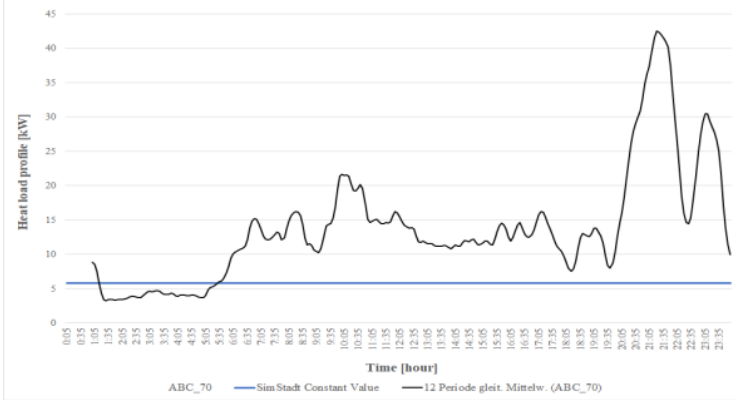

Figure 14: Measured DWD load profile for one sample residential building of Krosno

Approach based on Artificial Neural Network

Figure 15 and Figure 16 depict operation of the district heating network from sample winter and summer days. It can be seen that balancing the production and consumption in the network is a challenging task. In 
summer the difference between heat delivery to the network and consumption by the network is much more significant. This is the result of relatively small water mass flow rate in the network that leads to higher share of losses in heat production. Therefore, accurate predictions of domestic hot water consumption are of high importance and should be properly addressed in the methodology.

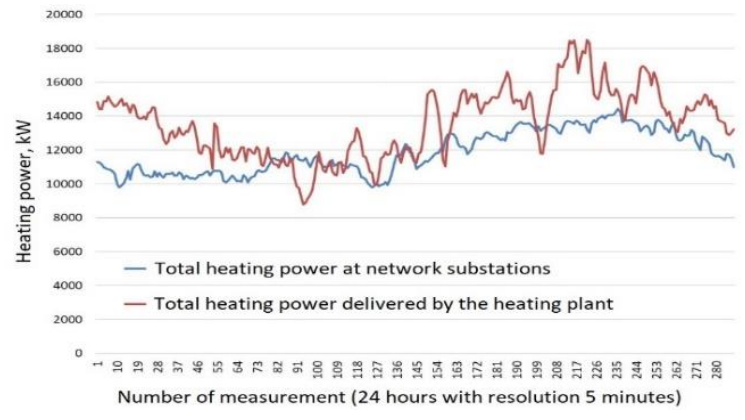

Figure 15: Operation of the heating network during a sample winter day

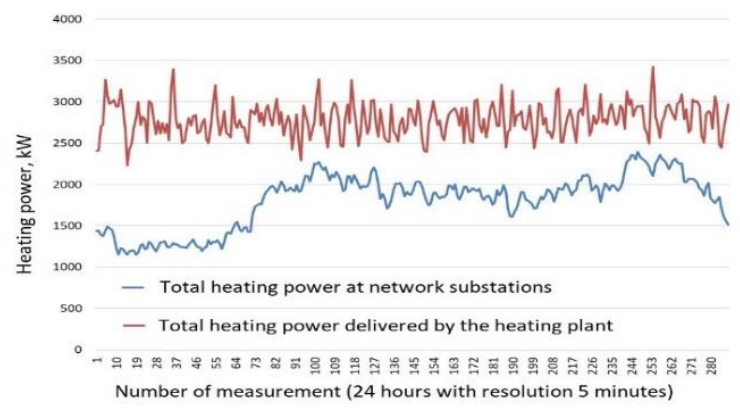

Figure 16: Operation of the heating network during a sample summer day

Efforts have been made to develop effective tools for load predictions, that would be beneficial for the heating plant operation. The traditional approach is usually based on regression models or neural network models (Potočnik et al., 2015; Cai et al., 2015; Johansson et al., 2017). As detailed long-term high-resolution measurements are available at the plant of the City of Krosno, an Artificial Neural Network (ANN) was also used for day ahead load predictions. The model was developed using heat load measurements at the heating plant outlet and the weather data from the Luft WS800-UMB weather stations installed on-site. The total number of data points was 264900 and $70 \%$ of this collection was used to train the network.

One of the critical issues of modelling loads using ANN based approach is identification of proper predictor variables that have the biggest influence on the predicted variable. Typically, outdoor temperature, wind speed and solar radiation are used (Cai et al., 2015). In extended studies also relative humidity and additional parameters can be used (Potočnik et al., 2015). The first model developed in this work (ANN-1) describes the heating load as a function of ambient temperature, wind speed and solar radiation. A two-layer feed-forward network with 10 sigmoid hidden neurons and linear output neurons was implemented. The ANN was trained using Bayesian
Regularisation which is recommended for noisy datasets. The results were in relatively good agreement with measurements, however the goodness of fit differed for different initiations of the model. This is typical situation in the case of ANN models (Potočnik et al., 2015). The value of $\mathrm{R}^{2}$ for the finally adopted ANN-1 was 0.944 . However, after tests of weather forecasts quality had been performed it was found that the radiative heat flux is predicted with relatively high error. Outdoor temperature and wind speed were in relatively good agreement with the measurement of the on-site weather station within the prediction horizon of 24 hours. Therefore, a second model (ANN-2) was built using ambient temperature, wind speed and type of day (integer variable representing working days, Saturdays, Sundays and holidays) and day duration (in hours). The $\mathrm{R}^{2}$ for the ANN-2 model was 0.976, greater than that of ANN-1. The next observation was that the resulting predictions had higher errors outside of the heating season. Therefore, for this period another model ANN-3 was developed using only the type of day and day duration as predictor variables. Although, the goodness of fit was low in this case $\left(R^{2}=0.173\right)$ the model improved predictions of the heating load out of the heating season. Results are depicted in Figure 17, Figure 18 and Figure 19.

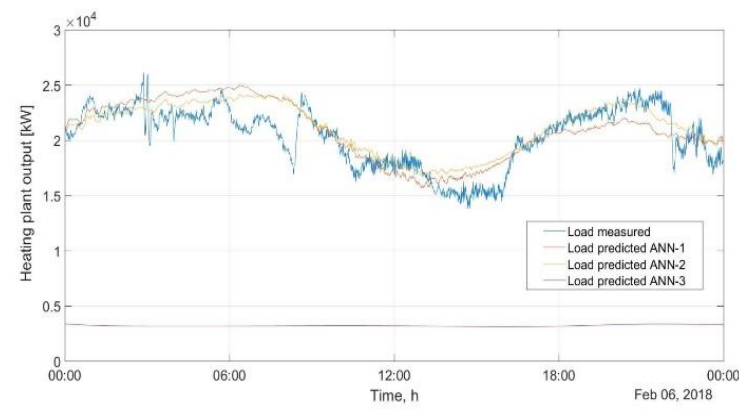

Figure 17: Validation of ANN models in winter day

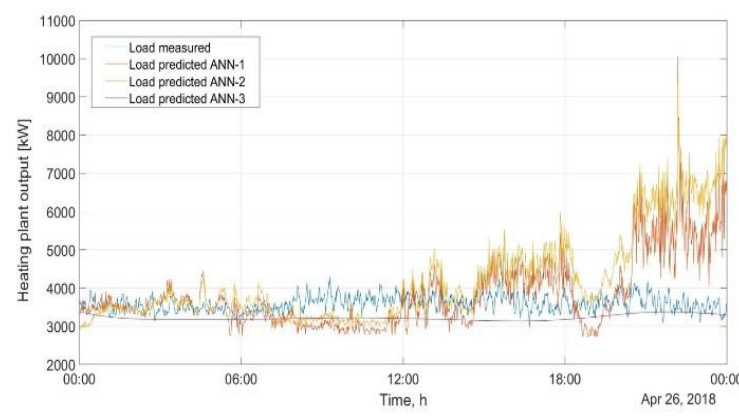

Figure 18: Validation of ANN models in spring day

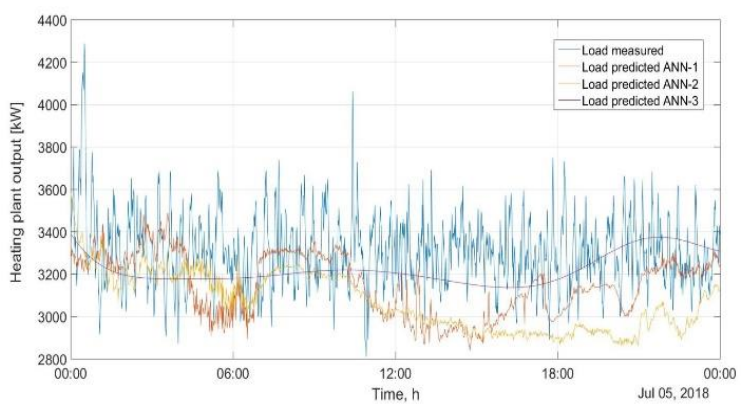

Figure 19: Validation of ANN models in summer day 


\section{Discussion}

The developed methodology for heat demand forecasting at district level using the Urban Energy Platform SimStadt can be seen as a useful tool for calculating the heat demand of individual buildings at the district scale (SHP) or city scale (City of Krosno). The replicability of the proposed method into different conditions, e.g. in Krosno, was successful, even if there had to be put much more effort in order to create a 3D CityGML model for Krosno; there is in Germany nationwide available 3D CityGML model in LoD1 and almost in LoD2 (Roschlaub and Batscheider, 2016).

The comparison between the annual measured and calculated values from SimStadt at the individual building level showed some considerable deviations; in case of some buildings even over $100 \%$. These deviations remain after summing them up to the district level, see Table 1.

Table 1: Summary of the deviations

\begin{tabular}{|c|c|c|c|}
\hline \multirow{2}{*}{} & \multirow{2}{*}{$\begin{array}{c}\text { Case } \\
\text { Study }\end{array}$} & $\begin{array}{c}\text { Indivi- } \\
\text { dual } \\
\text { Buildings }\end{array}$ & $\begin{array}{c}\text { Scale } \\
\text { Citywide } \\
\text { (Summing Up of } \\
\text { all Buildings) }\end{array}$ \\
\hline $\begin{array}{c}\text { Annual } \\
\text { deviations } \\
{[\%]}\end{array}$ & SHP & Up to 100 & 6 \\
\cline { 2 - 4 } & Krosno & Up to 150 & 2 \\
\hline
\end{tabular}

The deviations on the individual building level can be caused in case of a low energy consumption district like SHP by variability in user behaviour, which is treated in SimStadt with constants. In case of the City of Krosno, which is a city with many refurbished, old buildings the deviations can be also caused by treatment of refurbishment in SimStadt. However, while results at the individual building level vary, the citywide comparison fits very well.

Considering the hourly load profiles, the correlation between the measured and calculated load profiles is high. Even if the separate hourly values do not always fit together very well, load comparison at the city-scale is satisfying.

The calculated load profiles could be improved by implementing different user behaviour profiles, as well as different DWD load profiles into the SimStadt platform, but the effort doing it for large urban areas with several hundred or more buildings may not yield significant improvements. However, introducing this user behaviour profiles and DWD load profiles may yield interesting results.

The ANN-based approach to predict heating plant loads has an important disadvantage that should be emphasised. As soft computing models do not take into account physical characteristics of the modelled object, the evident disadvantage of this method is that it reflects only the heating profiles of DHS and cannot extrapolate. That is, if suboptimal settings and increased heat losses occurred in the period of collecting data, these characteristics will be present to the forecasting model. This is particularly the case of manually operated heating networks where the human factor has significant impact on the performance of the system (see Figure 15 and Figure 16). Therefore, in order to increase the forecastability of heating loads, a physically based bottom-up approach is recommended that is based on simulations of particular buildings as depicted in Figure 20. Such models would allow studies of changes such as disconnections of customer, thermal insulation of buildings or different building occupation schedules.

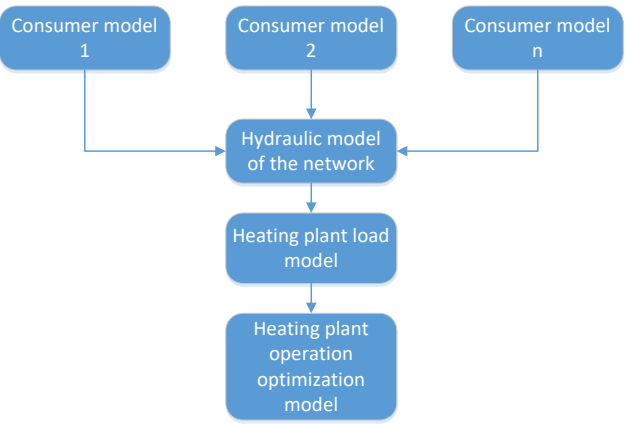

Figure 20: Recommended DHS optimisation framework

\section{Conclusion}

This paper presents two different tools for load predictions in urban areas. Special focus is put on the development of an urban area wide heat demand forecasting method, which is based on 3D CityGML models. In both methods the verification process using real measurement data was done in order to show the accuracy of the proposed method. The advantages and also disadvantages of both methods are shown and discussed.

One of the best advantages in case of using the Urban Simulation Platform SimStadt is fast and automatic calculation of citywide heat demand of hundreds to thousands individual buildings. The only input needed is the 3D CityGML model of the analysed area. In the case of Germany such models are available nationwide; however, year of construction and refurbishment ratio are not as readily available. The method was accurate at the district level, with deviations of $2 \%$ in Krosno and $6 \%$ in SHP.

A key advantage of the approach based on Artificial Neuronal Network is accuracy of predictions of heat load profiles when the system is operated without changes of either physical structure or consumer behaviour, for instance due to implementation of demand side management (DSM) measures. If the changes occur the model must be updated accordingly. This is a timeconsuming activity due to the fact that a relevant collection of measurement data must be built for this purpose. In contrast, the simulation-based method as addressed in the SimStadt software allows testing of effectiveness of different DSM measures at different buildings.

Both methods suffer from deviations in predicted values at the building level caused by the too general consideration of user behaviour and refurbishment ratio. Also, the consideration of thermal collectors for hot water demand is not included in the calculation methods proposed. Therefore, consideration of these features in 
future modelling efforts could lead to a better fit between measured and calculated values on the individual building level. However, in this paper the municipal scale is much more important than the individual building one, and both methods had high accuracy at the municipal scale. The good fit between measured and calculated hourly load profiles enables the forecasted hourly load profiles to guide energy generation, in order to match the demand and supply and finally increase the overall system efficiency and achieve the optimized performance.

Comparing both methods, it is difficult to decide which of them is better suitable for load predictions at citywide scale as each of them has substantially different functionality. SimStadt is designed to predict heat load based on building infrastructure and does not depend on the measurement data. The ANN based approach considers the district heating network as a black box and neither building envelopes nor consumer behaviour related factors are considered. If relevant measurement data within satisfactory sampling resolution is available the ANN based approach may be used for predictive control of the system operation. On the other hand, the main advantage of the SimStadt is the ability to perform extensive studies of changes and optimisation of building stock performance.

\section{Acknowledgement}

This work was carried out within the framework of the Polish-German Sustainability Research Programme STAIR in research project IntBioCHP titled: System integration of biomass fired cogeneration plants. The project is financed by German Federal Ministry of Education and Research and Polish Ministry of Science and Higher Education.

\section{References}

Braun, R., Weiler, V., Zirak, M., Dobisch, L., Coors, V., Eicker, U. (2018). Using 3D CityGML models for building simulation applications at district level. Improvements in simulation workflow to achieve a better fit between simulated and measured data. IEEE International Conference on Engineering, Technology and Innovation (ICE/ITMC). No. 978-1-5386-14693/18/\$31.00. 2018 IEEE.

Cai Q., Wang W., Wang S. (2015). Multiple Regression Model Based on Weather Factors for Predicting The Heat Load of A District Heating System in Dalian, China-A Case Study. The Open Cybernetics \& Systemics Journal, 2015, 9, 2755-2773.

DIN e.V. German Institute for Standardization. (2010). DIN V 18599 - Energy efficiency of buildings Calculations of the net, final and primary energy demand for heating, cooling, ventilation, domestic hot water and lighting - Supplement 1: Balancing of demand and consumption. [In German].
Eurostat (2016). The EU in the world.

Gröger et al. (2012). OGC City Geography Markup Language (CityGML) Encoding Standard. OGC Doc. No. OGC 12-019.

Heat Roadmap Europe (2017). Heating and cooling facts and figures. June 2017.

https://heatroadmap.eu/heating-and-cooling-energydemand-profiles/

IWU (2015). German Building Typology.

Johansson Ch., Bergkvist M., Geysen D., De Somer O., Lavesson N., Vanhoudt D. (2017). Operational Demand Forecasting. In: District Heating Systems Using Ensambles Of Online Machine Learning Algorithms. Energy Procedia 116, 208 - 216.

Monien, D., Strzalka, A., Koukofikis, A., Coors, V., \& Eicker, U. (2017). Comparison of building modelling assumptions and methods for urban scale heat demand forecasting. Future Cities and Environment 3(1), 113. https://doi.org/10.1186/s40984-017-0025-7

Nouvel, R., Zirak, M., Coors, V., \& Eicker, U. (2017). The influence of data quality on urban heeating demand modelling using 3D city models. Computers, Environment and Urban Systems 64, 68-80. https://doi.org/10.1016/j.compenvurbsys.2016.12.005

Potočnik P., Strmčnik E., Govekar E. (2015). Linear and Neural Network-based Models for Short-Term Heat Load Forecasting. Strojniški vestnik. Journal of Mechanical Engineering 619, 543-550. DOI:10.5545/sv-jme.2015.2548.

Roschlaub, R., Batscheider, J. (2016). An inspirekonform 3D building model of Bavaria using cadastre information, lidar and image matching. The international Archives of the Photogrammetry, Remote Sensing and Spatial Information Sciences. Volume XLI-B4. 2016. XXIII ISPRS Congress. 1219 July 2016. Prague. Czech Republic.

SimStadt - Urban Simulation Environment. Available: http://simstadt.eu (Accessed: 2018, April 18).

Strzalka., A., Bogdahn, J., Coors, V., \& Eicker, U. (2011). $3 \mathrm{D}$ city modelling for urban scale heating energy demand forecasting. ASHRAE HVAC\&R Research Journal, Special Issue: Indoor air quality, ventilation and energy conservation in buildings: Innovation and Integration (Part 1) 17(4), 526-539. http://dx.doi.org/10.1080/10789669.2011.582920

UNEP Report (2017). United Nations Environment Programme: District Energy in Cities. Unlocking The Potential Of Energy Efficiency And Renewable Energy. http://www.districtenergyinitiative.org/sites/default/fi les/publications/districtenergyreportbook07032017532.pdf 